\title{
Environmental origins of hypertension: phylogeny, ontogeny and epigenetics
}

\author{
Melvin Khee-Shing Leow
}

Hypertension and renal parenchymal disease are intricately linked. Primary renal parenchymal disease can impact on sodium and volume regulation and lead to hypertension, while arterial hypertension can induce renal parenchymal injury and precipitate renal dysfunction. The examination for clues to the environmental origins of renal disease and hypertension necessitates an approach that integrates epidemiology, clinical medicine, developmental biology, environmental science and epigenetics, such that the manner in which genes and the environment interact can be better understood to pave the way for innovative management paradigms with regards to prevention, diagnosis and treatment. This review summarizes the extant literature and provides cogent arguments for the need to evaluate chronic adult onset disease models such as hypertension and renal disease from the modern perspective that takes into account prenatal exposures, the intrauterine environment and development, postnatal growth and transgenerational epigenetic modifications with their attendant future disease risk from the individual to the population level.

Hypertension Research (2015) 38, 299-307; doi:10.1038/hr.2015.7; published online 19 February 2015

Keywords: Environment; epigenetics; phylogeny; ontogeny

\section{INTRODUCTION}

Essential or primary hypertension is a polygenic disorder, with genetic and environmental interactions driving its expression. Its diagnosis as a chronic medical disorder is based on defining arbitrary thresholds of blood pressure (BP) on the Gaussian distribution beyond which morbidity and mortality increase as evidenced by data of large-scale prospective epidemiological population studies. ${ }^{1-4}$ Hypertension is aptly defined as 'the inability of multiple compensatory mechanisms involved in the control of $\mathrm{BP}$ to maintain the pressure within appropriate limits' ${ }^{5}$ The impact of restoration of $\mathrm{BP}$ to a range below the diagnostic cutoffs is obvious from the significant health benefits and improved survival when hypertension is adequately treated. ${ }^{6,7}$

The physiological control of BP is a function of hemodynamics, rheology, neural inputs and a myriad of vasoactive peptides and hormones. ${ }^{8-11}$ Of these, the kidneys assume primary importance in the long-term control of BP. ${ }^{12,13}$ Arterial BP and renal output of sodium and water form a classic negative feedback system. When this becomes dysfunctional, uncontrolled hypertension injures the kidneys, which in turn elevate the BP via positive feedback. ${ }^{14}$

The medical model of disease addresses hypertension by elucidating mechanisms or 'proximate' answers in terms of 'how' the causation came about. However, a broader perspective embracing the theme of natural selection as the supreme organizing principle is necessary to unravel the 'ultimate' answers as to 'why' hypertension occurs.

\section{CLUES FROM EPIDEMIOLOGY}

Interesting epidemiological findings ignite biologically plausible hypotheses regarding how the forces of nature have shaped the hypertension landscape. For instance, BP is found to be inversely proportional to altitude above sea-level. Residents at high altitudes show lower BPs despite having higher blood viscosity due to elevated hematocrit and secondary polycythemia from lower oxygen tension. ${ }^{15}$ Evolutionary inference to the phenotypic mean differences between highland and lowland inhabitants, successfully explains why the BP should be lower at higher altitudes. ${ }^{16}$

A geographical distribution of prevalence of hypertension similarly occurs in relation to air temperature as climate produces a latitudinal cline in heat adaptation and hypertension susceptibility. Environmental biologists have postulated that BP should be negatively correlated to mean annual temperature worldwide. ${ }^{17}$ This stemmed from the thesis of Carl Bergmann that homeotherms living in colder climates will be larger than those in warmer climates by virtue of thermal advantage of a smaller surface area to volume ratio of a larger body size, which in turn correlates positively with BP. ${ }^{18,19}$ Local brief exposure to intense cold elevates BP transiently via vasoconstriction initially. Through the acclimatization process, the BP eventually normalizes among residents in colder environs, with consequent lower BPs compared with inhabitants in warmer climates. Although inconclusive, populations from hot environments are more susceptible to hypertension than those residing in cold climates, probably due to the inherent need by the former for increased vasomotor tone as a 
defense against excessive vasodilatation to facilitate heat loss in response to hot weathers. ${ }^{20}$ Ancestral adaptation to selective pressures during the migration of early humans out of Africa probably influenced the expression of genes influencing renal salt handling and arterial vessel tone and hence the differing susceptibility to hypertension between peoples. ${ }^{20}$

Geographic and spatial distribution of hypertension also appear to be mediated in part by dietary intake of potassium/sodium and the expression of genes governing vasoactive hormones, such as angiotensin II, aldosterone, natriuretic peptides and urinary excretion of sodium and potassium. ${ }^{21}$ Closely related to dietary exposure is the role played by economic transition as reflected by the rising prevalence of hypertension in developing countries. The existence of a social economic status gradient with greater frequency of higher BP among urban-dwellers compared with their non-urban counterparts underscores this point. $^{22}$

Demography and anthropology provide useful clues on ethnic and racial BP differences in any given environment. The angiotensinogen H1 haplotype is linked to higher levels of plasma angiotensinogen and hypertensive status in black families of African descent. ${ }^{23}$ Angiotensin I-converting enzyme (ACE) single-nucleotide polymorphisms have yielded compelling data, such as the ACE4 'A' allele being associated with hypertension among the blacks. ${ }^{24}$ Finally, epidemiology has unraveled a myriad of environmental factors, including vitamin deficiency, environmental toxins, nephrotoxic drugs, obesity and lifestyle factors such as psychological stress, sleep deprivation, smoking, salt/alcohol intake and occupational toxins, as likely contributory.

\section{PHYLOGENY AND EVOLUTIONARY PERSPECTIVES}

To understand the origin of hypertension in modern day humans, it is instructive to approach it from both evolutionary and comparative biology angles. Modern medicine stands to gain substantially by studying phylogeny as elegantly demonstrated by how physiology and systems biology are informed with respect to evolutionary principles that operate across the different vertebrates and nonvertebrates species.

The transition from a salt-plentiful marine aquatic to terrestrial life with salt paucity requires significant endocrine adaptation. Primitive bony fishes possess renal renin and juxtaglomerular cells during their early evolution but lack a feedback mechanism controlling renin release from the macula densa as the latter evolved later in vertebrate phylogeny probably stemming from their exposure to high sodium levels in the oceans since the primeval era. Amphibians and reptiles also lack a macula densa and extraglomerular mesangium, and avian kidneys have a transitional macula densa but no extraglomerular mesangium. The juxtaglomerular apparatus in birds is transitional between mammals and lower vertebrates. ${ }^{25}$ In non-mammalian vertebrates, adrenocortical steroids act on several sites, including the gills, skin, nasal glands or salt glands in addition to the kidneys. ${ }^{26}$ However, mineralocorticoids are mainly nephrotropic in mammals. As vertebrates expanded their habitats from aquatic to terrestrial environments, adaptation to life on land requires obligatory transformations in the osmoregulatory and cardiovascular systems to counter both dehydration and gravity and thus necessitates an elaborate reninangiotension-aldosterone system (RAAS) to be evolved. Comparative biology of the RAAS reveals that the site of action of these vasoactive hormones was the systemic and preglomerular vasculature in primitive vertebrates. Indeed, it was only in the later stages of phylogeny that the RAAS act directly on renal tubules. ${ }^{26}$ Hence, the available evidence suggests that the RAAS evolved with a close relationship to BP homeostasis. ${ }^{25}$
'Reverse' phylogenetics attempts to identify novel sodium-regulating and vasoactive hormones from comparative fish studies to provide insights into relevant regulatory pathways that deserve deeper scrutiny among humans. ${ }^{27}$ Although nitric oxide is now the well-established endogenous vasodilator produced by the vascular endothelium, hydrogen sulfide has recently been shown to be a potent endogenous vasodilator. To aid our understanding of its phylogenetic significance and environmental trends, hydrogen sulfide was examined for vasoactivity in all vertebrate classes, including sharks, toads, alligators, ducks and humans. The data suggested that hydrogen sulfide is an ancient and versatile vasoregulatory molecule that switches its function according to species-specific and organ-specific homeostatic requirement depending on the nature of the habitat environment. $^{28}$

Phylogeny is thus successful by providing better clarification and substantiating well the notion that hypertension is the consequence of maladaptive responses by homeostatic animals operating through highly conserved genes under selective pressures.

\section{GENE-ENVIRONMENT INTERACTIONS AND BP REGULATION}

Hypertension is the product of susceptibility genes in a mismatched environment. In this connection, the family history, age, gender, race, socioeconomic status, nutrition, salt intake, obesity, physical activity, traffic noise, psychological stress, smoking, climate and various toxins are all relevant. It is debatable if they operate independently or work via an overactive sympathetic nervous system. ${ }^{29-32}$ In analyzing the contribution of nature and nurture, the kidneys turned out to be a predominant common mediator.

One of the key physiological functions of the kidneys is that of BP regulation via the mechanism of pressure-natriuresis. ${ }^{33}$ Mathematical modeling demonstrated that this servomechanism would have an infinite gain, which means that it is capable of totally restoring BP to a homeostatic set-point at which sodium/water fluxes are balanced, over and above other biological subsystems contributing to BP control. ${ }^{34}$ Any excess dietary sodium intake is prevented from raising the BP due to paralleled matching increase in the level of natriuresis consequential to increased blood volume and pressure. Although such a mathematical model explains the physiology well in a general sense, it is necessary to integrate into the model how adaptive genetic mutations may alter the renal tubular sodium transport and excretory capacity to account for observed differences in salt sensitivity between races. Hence, it is posited that appropriate genes must endow the acclimatized kidneys with capability of flattening the pressure-natriuresis curve characteristic and predisposing the early humans living in the African savannahs to sodium sensitivity. ${ }^{35}$ Salt sensitivity as such refers to the elevation in BP from short-term manipulations that increase sodium intake thought to predispose individuals habitually on a high salt diet to hypertension. Such genetic drifts perpetuated during the out-of-Africa expansion and explain the origin of the risk of salt-sensitive hypertension among more African Americans than Caucasians in the modern environment (Figure 1). The efficiency of this pressure-natriuresis negative feedback loop is limited by the total available nephron glomerular filtration surface of the kidneys, a variable that may be both genetically and environmentally determined. ${ }^{36}$ It is conceivable that the predicted capacity of the kidneys for pressure-natriuresis may be outstripped either by a very chronic excessive loading of salt or by absolute reduction in nephron number. 


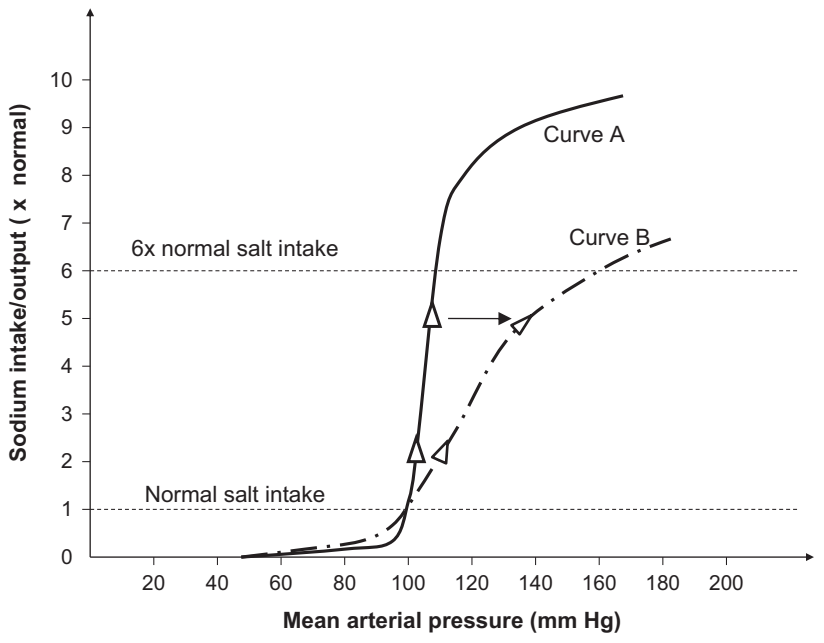

Figure 1 The pressure-natriuresis relationship allows for a tight control of $\mathrm{BP}$ within a narrow physiological range appropriate for cardiovascular health and survival despite large increases in salt intake, which is approximately matched by equal amounts of sodium excretion, as illustrated by curve $\mathrm{A}$ (solid line). For a salt-sensitive individual (curve B, dotted line) endowed with ancestral genetic modifications selected for a higher thresholds for sodium excretion and elevated capacity for sodium conservation, even modest intake of salt will result in a significant increase in arterial BP.

\section{THE PATHOGENIC ROLE OF SALT AND OTHER DIETARY FACTORS}

Sodium has long been suspected as an etiology of hypertension since a century ago. ${ }^{37}$ Animal studies for years have also consistently shown that high salt intake induced elevation in $\mathrm{BP}{ }^{38}$ Salt began as a trivial component in the diet of prehistoric humans for millennia. Populations around the world who consume large quantities of salt suffer from high rates of hypertension, compared with hunter-gatherer tribes subsisting on diets low in salt. ${ }^{39}$ It is not surprising therefore that hypertension is an esoteric disorder in societies on low salt diets. ${ }^{40,41}$ Research subsequently proved that lowering the intake of salt also decreased BP. ${ }^{42-44}$ Unfortunately, sodium consumption has been creeping steadily upwards, from $2300 \mathrm{mg}$ daily in the early 1970 s to about $3300 \mathrm{mg}$ just a decade ago. ${ }^{45}$ The average hunter-gatherer's sodium intake is only about $20 \mathrm{mg}$ in stark contrast. ${ }^{46}$ The human body only requires about $180 \mathrm{mg}$ per day to replace losses in perspiration and urinary and gut losses. ${ }^{47}$ Increased sodium in the circulatory system induces vasoconstriction via a recently discovered mechanism mediated by endogenous ouabain and the sodiumcalcium exchanger of vascular smooth muscles, which further raises $\mathrm{BP}$ and reduces tissue perfusion. ${ }^{48}$

From an evolutionary standpoint, the genetic variants which produced salt-sensitive phenotypes that favored salt retention by an avid RAAS among the early human beings who survived in the hot, dry conditions were positively selected. Although salt sensitivity confers a survival advantage, it lowers the threshold for BP elevation with salt excess (Figure 2). As a corollary, the black Africans serve as a good model of salt sensitivity as a risk for hypertension. Their ACE polymorphisms and angiotensinogen mutants have so evolved as to render ACE inhibitors far less effective as antihypertensive agents than diuretics monotherapy in line with prediction based on the survival advantage conferred by natural selection in people living in arid, hot climates. ${ }^{49}$ Lower renin activity among African Americans increases distal tubular delivery of sodium and tubular hyperperfusion of the macula densa, which could also explain the greater antihypertensive effectiveness of thiazide diuretics compared with either beta-blockers or ACE inhibitors in this racial group. ${ }^{50-54}$

Dietary intake of potassium, calcium, magnesium, polyunsaturated fatty acids and alcohol are also relevant. ${ }^{55-56} \mathrm{BP}$ has long been found negatively correlated with potassium. ${ }^{54}$ Similarly, adequate polyunsaturated fatty acid intake has been shown to very modestly lower $\mathrm{BP}$, probably via prostaglandin pathways. ${ }^{55} \mathrm{~A}$ significant correlation exists between mean daily alcohol intake and BP; in particular, in most alcoholic hypertensives whose daily consumption exceeded $80 \mathrm{~g}$, BP normalized with abstinence and increased again following resumption of drinking, showing a definite dose-response effect. ${ }^{56,57}$

Diseases of civilization often have their developmental origins based on the 'thrifty genotype' hypothesis by late James Neel. ${ }^{58}$ In a similar vein, 'thirsty genes' conserved by our hunter-gatherer ancestors who survived in situations of salt scarcity might have conferred a survival advantage to defend against many volume-depleting states such as profuse perspiration, hemorrhage or diarrheal illnesses commonly encountered in austere environments. ${ }^{59}$ Our present salt- and waterconserving genetic legacy is thus evolutionarily derived from ancestral hominid origins who successfully withstood the privation of terrestrial life on arid and salt-scanty inlands by natural selection. Hence, the 'hypertensive' genes that shaped the phenotype of the fittest are clearly an adaptation optimizing the organism for survival in the challenging ecological land niche. Expectedly, our ancestors who lived during the era before salt becomes excessive would not have been afflicted by hypertension. Indeed, historical records suggest that hypertension is very much a modern day disease unveiled by the high salt content of our present day diets. ${ }^{60,61}$

\section{RENAL SIZE AND NEPHRON NUMBER}

Allometric scaling has predicted a coherent relationship between body weight and renal size such that its allometric constant lags behind the allometric constant of blood volume and body size. ${ }^{62}$ Accordingly, a renal functional deficit becomes apparent when linear body growth is propelled to the genetic limits in the nutritionally enhanced environment following cessation of further kidney growth at puberty or when intrauterine growth restriction retards kidney growth proportionally greater than the overall body size. ${ }^{63}$ The theory of allometry predicts that hypertensive people will have glomeruli, tubules and kidney sizes smaller than a population of normotensives. ${ }^{64}$

In 1988, Brenner et al. ${ }^{65}$ proposed that individuals endowed with fewer nephrons would be at a higher risk for development of hypertension later in life. On average, a human kidney has about 844000 nephrons. ${ }^{66}$ A reduction in size of glomeruli and nephron number sufficient to impact on glomerular filtration surface area will predispose the affected individual to alteration of the BP set-point and hypertension. Since the $1930 \mathrm{~s}$, the association between low nephron number and hypertension had already been described. ${ }^{67}$ Series of human autopsies confirmed that the Australian aborigines who have the lowest number of nephrons are also the group with the highest rates of renal failure and hypertension. ${ }^{68}$ Postmortem threedimensional stereology of those with primary hypertension compared with normotensive matched controls showed significant correlations between low nephron number and hypertension, with the hypertensive group with fewer nephrons (median: 702379 vs. 1429200$).{ }^{69}$

Munich-Wistar-Fromter (MWF) rats with inherited nephron deficit compared with their wild-type Wistar rat controls spontaneously develop hypertension in the course of their growth. ${ }^{70}$ It has been shown that the insulin-like growth factor (IGF) system is crucial in nephogenesis and that both insulin-like growth factors I and II availability are deficient during the critical period of kidney 


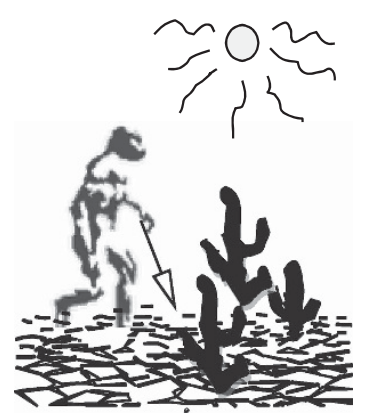

Prehistoric physically active huntergatherer humans in hot terrestrial environment predisposing to perspiration with sodium loss

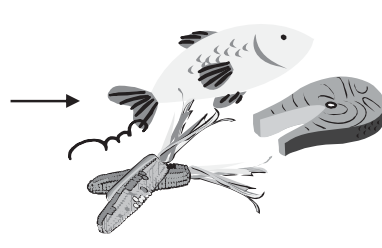

Diet with low salt content

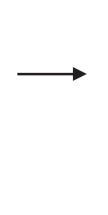

Heritable epigenetic modifications and gene polymorphisms promoting a salt sensitive phenotype that conferred survival advantage in environment of salt scarcity

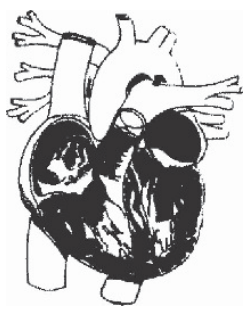

Healthy cardiovascular system with normotensive blood pressures

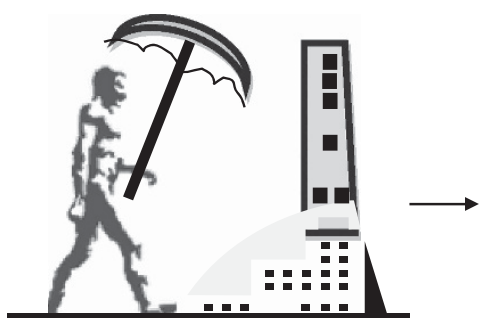

Modern and largely sedentary humans with capacity to alter environmental temperatures (eg. air conditioning) regardless of climate

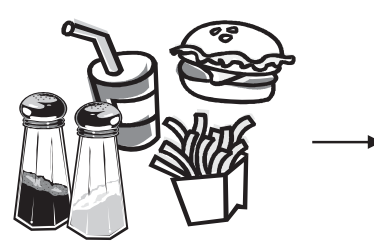

High salt diet (eg. fast food) with excess refined sugars and saturated fats

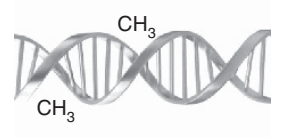

Ancestral genes regulating sodium and water metabolism now promotes salt and fluid retention

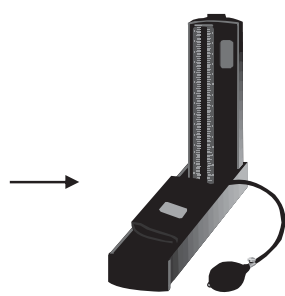

Increasing incidence of hypertension on a global scale in the present era

Figure 2 Schematic illustrating the manner of gene-environmental interactions that led to the conservation of heritable genetic changes favoring a salt-sensitive phenotype that predisposes to hypertension in a mismatched environment of sodium excess in the current age.

development in MWF rats, leading to lower nephron numbers. ${ }^{71}$ In a sheep model of glucocorticoid-induced hypertension, prenatal dexamethasone exposure during the nephrogenesis period when compared with a controlled group resulted in hypertensive sheep at 7 years of age, with significantly lower total nephron number associated with glomerulomegaly as determined by unbiased stereology. ${ }^{72}$

Nephron number and glomerular size is negatively correlated with age and positively correlated to kidney mass. ${ }^{73}$ That BP gradually increases with age could therefore be partly explained by a progressive decline in nephron number in addition to arteriosclerosis. Metabolic rate correlates with body surface area and the latter correlates better with kidney mass and total glomerular volume but not to the number of glomeruli. ${ }^{74}$ Thus, kidney filtration capacity adapts to metabolic demands by altering the glomeruli size instead of changing glomerular number. ${ }^{75}$ Such adaptation favors hyperfiltration injury and glomerulosclerosis with consequent risk of nephron loss.

Others have shown that reduced nephron number is an essential but not a sufficient condition for nutritionally induced hypertension. Fetal nutrient deficiency in the form of asymmetric growth restriction results in redistribution of blood flow from organs such as the skeletal muscles, liver and kidneys to organs critically important for fetal survival such as the heart and brain. The kidneys at this vulnerable period of growth restriction suffer from a permanently reduced number of nephrons. Following accelerated postnatal growth, the increased body mass with consequent elevated excretory load becomes excessive for the reduced excretory capacity of the kidneys, which therefore undergo intrarenal compensatory mechanisms of glomerular and tubular hypertrophy with single nephron hyperfiltration and intrarenal renin-angiotension system activation, setting the stage for development of hypertension. ${ }^{76}$

\section{INSIGHTS FROM ONTOGENY AND EPIGENETICS}

The complex gene-environment interactions as the pathway for development of hypertension have much support from studies of ontogeny. Embryologic and antenatal events that restrict fetal growth have been shown to impair nephrogenesis, and the price of that low nephron endowment is the heightened risk of hypertension and renal disorders in later life. Much remains to be learned about how including the postnatal environment nutrition affects nephrogenesis. The connection between the long-term effects of early childhood nutrition on cardiovascular and renal disorders in late adulthood deserves more investigation in this age of epigenetics.

Accordingly, the 'thrifty phenotype' hypothesis of Hales and Barker ${ }^{77}$ proposes that the plasticity of the fetal genome facilitates in utero programing via epigenetic mechanisms to allow the fetus developing in an antenatal environment of scarcity to anticipate the environment it will encounter postnatally. Intrauterine growth constraint has been shown in both humans and animals to lead to their newborns having fewer and smaller glomeruli, which impair the renal pressure-natriuresis servomechanism by operating it at a higher BP range. ${ }^{78}$ Barker et al. ${ }^{77}$ demonstrated an inverse correlation between birth weight and incidence of hypertension and cardiovascular disease. 


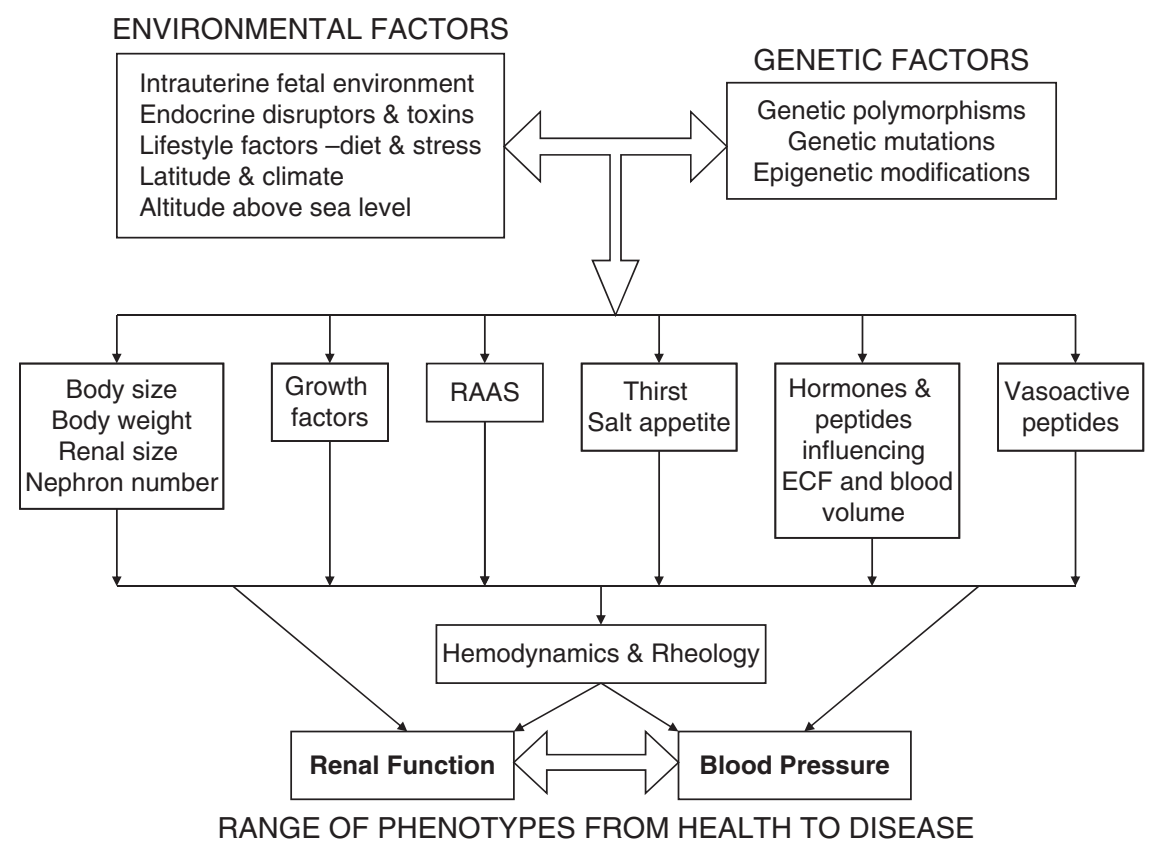

Figure 3 Summary of the nature of environmental interactions with genetic factors that impact on kidney function and BP which may in turn influence the risk to development of renal disease and hypertension. RAAS, renin-angiotensiin-aldosterone system, ECF, extracellular fluid.

The well-established rapid catch-up growth observed among intrauterine growth-restricted individuals with smaller kidneys during postnatal development may amplify the discrepancy between the allometric proportions of somatic size to the kidneys, which may result in dysfunction of the pressure-natriuresis in physiological blood volume regulation and therefore correlate with hypertension in later life. Together with the iming of onset of the pubertal growth spurt, the growth trajectories during childhood and adolescence can influence $\mathrm{BP}$ in adulthood in the future. ${ }^{79}$

Fetal undernutrition thus has a lasting impact on BP programing as shown by the associations between birth weight and cardiovascular disease supported by animal experiments and human data. Yet, the risk for hypertension in relation to birth weight may be more complex than earlier suspected as suggested by a recent meta-analysis. Individuals born at the other extreme, namely high birth weight, are also prone to hypertension during childhood. Enigmatically, as they grow older, their susceptibility to hypertension paradoxically becomes lower than those born with normal birth weight. ${ }^{80}$ Maternal diet may be a crucial factor as this probably influences intrauterine availability of fetal nutrition. A recent murine study showed that maternal low protein diet during gestation apparently has the capability of programing reduced nephron number and hypertensive effects in offsprings up to the second generation. This trans-generational programing is likely the result of stable, heritable epigenetic changes induced by maternal diet. ${ }^{81}$ To resolve how much does genetics as opposed to intrauterine environmental factors play in fetal origin of hypertension, twin studies offer a unique opportunity to dissect their relative contributions to birth weight and cardiovascular disease risk. In one twin cohort, it was found that low birth weight was associated with insulin resistance, lower high-density lipoprotein and shorter height within both the dizygotic and monozygotic twin pairs with discordant phenotypes, suggesting these associations are partly independent of genetic factors. ${ }^{82}$ Relevant to this is the finding of greater aortic intimal media thickness among fetuses with intrauterine growth restriction compared with those with fetal weight appropriate for gestational age. When followed up postnatally, the systolic BP of those in the intrauterine growth restriction group was significantly higher than the appropriate for gestational age group, and this correlated well with the prenatal and postnatal aortic intimal media thickness. ${ }^{83}$ The late effects of childhood nutrition likely have a role but remained unclear. Overnutrition may be detrimental as a rat model had demonstrated that early postnatal overfed rat pups enhanced postnatal nephrogenesis with a $20 \%$ increase in glomerular number but paradoxically led to increased proteinuria and glomerulosclerosis and systolic hypertension. Evidently, there must be other reasons apart from reduced nephron number alone that influence BP. ${ }^{84}$

Environmental influences, including the 'intrauterine climate' and the maternal-fetal interface, may interact adversely with the kidneys to promote the expression of hypertension in adult life. Experimental evidence clearly shows that the early nutritional perturbations in the intrauterine environment can have lasting epigenetic programing effects on cellular and organ development, which then results in obesity and hypertension in adult life. Research now focuses on mechanisms of organ dysfunction and on refining the understanding of the interaction between common elements of adverse perinatal conditions, such as nutrition, oxidants and toxins exposures, taken together as part of the entire range of environmental factors that can interact with the genetic makeup to cause hypertension (Figure 3). Modulating developmental programing offers the hope of a critical window of opportunity to reverse programing and prevent or reduce related adult-onset diseases. The notion of far reaching effects of dysfunctional or compromised maternal nutrition and health on the perinatal milieu that drives the fate of vasculogenesis and nephrogenesis is increasingly appreciated. ${ }^{85}$ Metabolic outcomes and changes in renal function and hypertension are correlated to the rates of antenatal and postnatal growth. Ontogeny as such reveals invaluable clues regarding the pathogenesis of perinatal programing and provides opportunity for intervention at the prenatal stage for prevention of hypertension, renal and metabolic disorders. 


\section{ETIOPATHOGENESIS AND MOLECULAR MECHANISMS}

The molecular mechanisms underlying the etiopathogenesis of a disorder with an environmental origin would expectedly involve fundamental biochemical interactions with the genome. In this scheme, environmental factors can exert their profound impact on gene expression via epigenetic modifications, which represents stable, heritable yet potentially reversible modifications without any mutations of the genetic sequence per se. DNA methylation, histone modifications, microRNA and genomic imprinting are the epigenetic processes that typically govern the environmental-genetics nexus. In contrast, actual mutations causing hypertension are probably very rare, such as exemplified by hypertension from a gain-of-function mutation of the aldosterone receptor. ${ }^{86}$ Another example would be the mutations of the WNK kinases due to large intronic deletions or missense mutations of the WNK family of serine-threonine kinases affecting sodium-potassium homeostasis at the distal nephron, causing a monogenic hypertension with Mendelian inheritance. ${ }^{87}$

The whole range of systems that regulate $\mathrm{BP}$ over the short, intermediate and long term might be subjected to any of these epigenetic changes. BP is a function of cardiac output, blood volume and vascular resistance. Cardiac output is dependent on myocardial contractility and autonomic nerve discharge, while blood volume is dependent on sodium and hydration status together with systems that control fluid balance such as the kidneys that act according to sophisticated endocrine signals, such as the mineralocorticoids and glucocorticoids. Indeed, an epigenetic pathway for aldosterone signaling has been identified whereby the control of epithelial sodium channel-a $(\mathrm{ENaC} \alpha)$ subunit gene expression in the nephron collecting duct is affected by histone H3 Lys-79 methylation of chromatin associated with the $\mathrm{ENaC} \alpha$ promoter, which may be implicated in renal fibrosis and hypertension. ${ }^{88}$ It is likely that many more dysfunctions of the local and systemic components of BP regulation leading to hypertension will eventually be found to have an epigenetic basis at the gene-environment interface.

\section{OBESITY, INSULIN RESISTANCE AND URIC ACID}

Obesity, metabolic syndrome and type 2 diabetes are conditions now understood to have their origins partly rooted in early developmental history. The association between gout, obesity, diabetes, kidney disease, hypertension and cardiovascular disease has been appreciated as early as the $1800 \mathrm{~s} .{ }^{89}$ Notably, humans have higher serum uric acid levels than most other mammals due to mutational silencing of the uricase gene during hominoid evolution in the Miocene epoch between 8 and 24 million years ago, an event postulated to confer a selective advantage through $\mathrm{BP}$ homeostasis mediated by uric acid in low-salt environments. ${ }^{90}$ Splice variants of the SLC2A9 gene, which encodes a combination high-capacity urate transporter and highaffinity glucose-fructose transporter, have been found to contribute to $5-10 \%$ of serum uric acid concentrations in Homo sapiens. ${ }^{91}$ This has important bearings because of the ever increasing global consumption of refined sugar (sucrose) and fructose since the past two centuries in the developed world that has been linked to higher serum uric acid and the metabolic syndrome. ${ }^{92}$ Fructose metabolism results in a rapid decline in ATP and increases uric acid production. ${ }^{93}$ High-fructose diet in humans has been shown to induce both hypertension and many features consistent with the metabolic syndrome. ${ }^{94}$ As a corollary, decreasing uric acid levels can reverse hypertension and many features of the metabolic syndrome. ${ }^{95}$ Fructose-induced hyperuricemia might therefore be an important dietary mechanism accounting for the rising incidence of hypertension worldwide from a public health standpoint. ${ }^{95}$ Recent experimental and clinical evidence now strongly suggest that elevated uric acid may lead to hypertension. ${ }^{96-99}$ As hyperuricemia has been shown to precede the development of hypertension, it is no longer assumed to be a consequence of hypertension but rather as an antecedent factor that has a crucial role in the pathogenesis of hypertension. ${ }^{100}$ Its welldocumented antiangiogenic effects implies it might be responsible for reduced nephron number and low birth weight in babies born to mothers with preeclampsia and hyperuricemia based on the fact that uric acid transfers freely between maternal and fetal circulation. ${ }^{101}$

\section{ENDOTHELIUM AS ENVIRONMENT-ENDOCRINE INTERFACE}

The endothelium lining the blood vessels elaborates a host of paracrine vasoactive factors, which serve as major determinants of vascular structure and function. ${ }^{102}$ Vasodilatory substances, including nitric oxide and prostacyclin, and vasoconstrictor substances such as thromboxane A2 and endothelin-1 are finely modulated by the endothelium, which in turn alters vascular tone and BP. ${ }^{103}$ As blood is a major carrier of exogenous and endogenous molecules, its constant contact with the endothelium as it courses through the $100000 \mathrm{~km}$ of vasculature makes the endothelium one of the largest endocrine organ that interfaces between the external environment and the multi-organ systems of the human body. Vascular physiology, which contributes significantly to BP regulation, is itself a very complex area that is controlled by the endothelium, smooth muscles of the vessel wall and a whole array of cells, hormones and cytokines (for example, adrenomedullin, natriuretic peptides (atrial natriuretic peptide/brain natriuretic peptide/C-type natriuretic peptide), vasopressin (arginine vasopressin), endothelin, angiotensin II, prostaglandins) operating via autocrine, paracrine and endocrine pathways, mostly via agonist-antagonist mode of action that allow fine-tuning of $\mathrm{BP}$ to accommodate a multitude of environmental challenges ranging from mundane to austere situations. ${ }^{104}$

Endothelial dysfunction is associated with impaired nitric oxide synthase (endothelial nitric oxide synthase) activity and endotheliumdependent vasodilatation. ${ }^{105,106}$ This contributes to elevations in BP, which further impairs endothelial function by positive feedback. Endothelial dysfunction therefore has a critical role in the development of hypertension. Adverse fetal nutritional supply affects endothelial function and increases hypertension risks through fetal programing. DNA methylation, posttranslational histone modification and chromatin-based mechanisms have been shown to influence endothelial function by affecting the expression of endothelial nitric oxide synthase. ${ }^{107,108}$ This area of science is still very much in its infancy and is likely to grow rapidly in importance as the complex functions of the endothelium are dissected with the cutting edge of epigenetics.

\section{ROLE OF ENDOCRINE DISRUPTORS}

Endocrine disruptors are exogenous chemicals that when absorbed into the body mimics or blocks hormones and disrupts normal body functions. This can occur though stimulation or suppression of hormone synthesis, alteration of hormone concentrations and kinetics, changes of hormone regulation, distribution and metabolism and thereby affecting the functions that endogenous hormones control. There are innumerable ways that endocrine disruptors can interfere with gene expression and therefore fetal development, which depend exquisitely on endocrine signals in the hormonal milieu of the intrauterine environment. Nephrotoxic substances can inflict permanent lesions to the developing kidneys of the fetus and lead to chronic proteinuria or even hypertension. ${ }^{109}$ 
Multiple lines of evidence suggest that endocrine disruptors may be responsible for much of the burden of chronic maladies that plague mankind, including cardiovascular disorders such as hypertension, obesity, diabetes, reproductive failure and cancer. ${ }^{110}$ Environmental endocrine disruptors such as dioxins and polychlorinated biphenyls (PCBs) have exceptionally prolonged half-lives of 7-10 years in the human body that have been shown to interfere with estrogen metabolism. Maternal exposure to endocrine disruptors has been found to correlate with placental levels following delivery, with potential detrimental long-term sequelae to the fetus. ${ }^{111}$ In utero exposure to environmental PCBs and dioxins have been found to be negatively associated with birth weight and postnatal growth until 3 months of age. ${ }^{112}$ As well, the level of PCBs is positively correlated to BP. ${ }^{113}$ This finding is supported further by NHANES 1999-2002 in which 7 of the 11 PCBs were found significantly associated with hypertension. The strongest adjusted associations with hypertension were found for dioxin-like PCB 126 and PCB 118, indicating that elevated PCBs is an independent risk factor for hypertension. ${ }^{114}$

The growing worldwide concern that endocrine disruptors can influence epigenetic mechanisms, chromosomal stability and gene expression implies the urgent need to evaluate the impact of environmental pollution on hypertension, especially in terms of the developing fetus, disease onset in adulthood and possible heritable epigenetic changes to affect hypertension risks to offspring in the future. Environmental exposure to persistent organic pollutants has been determined to be associated with changes in global DNA methylation levels in a human population. ${ }^{115}$ Moreover, endocrine disruptors can modulate epigenetic programing of the germ line during embryonic development and not only affect the developing offsprings but also transmit transgenerational adult onset disease. ${ }^{116}$

\section{CONCLUSIONS}

Hypertension and renal disease are both highly prevalent human afflictions with devastating morbidity and mortality. Their pathogenetic basis is now gradually understood to involve intricate pathways linking the environment with the genome via epigenetic mechanisms that are recently being unraveled. The hope is that the better insights of the environmental origins of hypertension and renal disease will allow us to explore novel ways to target these disorders and reduce the toll they currently exact on our species.

1 WHO Technical Report Series, No 628, 1978 (Arterial hypertension: Report of a WHO Expert Committee).

2 Asia Pacific Cohort Studies Collaboration. BP and cardiovascular disease in the Asia Pacific region. J Hypertens 2003; 21: 707-716.

3 Lewington S, Clarke R, Qizilbash $N$, Peto R, Collins R. Prospective Studies Collaboration. Age-specific relevance of usual BP to vascular mortality: a metaanalysis of individual data for one million adults in 61 prospective studies. Lancet 2002; 360: 1903-1913.

4 Lawes CMM, Vander Hoorn S, Law MR, Elliot WJ, MacMahon S, Rodgers A. BP and the global burden of disease 2000, part II: estimates of attributable burden. $J$ Hypertens 2006; 24: 423-430.

5 James GD, Baker PT. Human population biology and hypertension: evolutionary and ecological aspects of BP. In: Laragh JH, Brenner BM (eds). Hypertension: Pathophysiology, Diagnosis and Management. Raven Press: New York, USA, 1990, pp 137-145.

6 Collins R, Peto R, MacMahon S, Hebert P, Fieback MH, Eberlein KA, Godwin J, Qizilbash N, Taylor JO, Hennekens CH. BP, stroke, and coronary heart disease, part 2: short-term reductions in BP: overview of randomized drug trials in their epidemiological context. Lancet 1990; 335: 827-838.

7 BP Lowering Treatment Trialists' Collaboration. Effects of ACE inhibitors, calcium antagonists, and other blood-pressure-lowering drugs: results of prospectively designed overviews of randomized trials. Lancet 2000; 356: 1955-1964.

8 Biaggioni I. Sympathetic control of the circulation in hypertension: lessons from autonomic disorders. Curr Opin Nephrol Hypertens 2003; 12: 175-180.
9 Guyton AC. Long-term arterial pressure control: an analysis from animal experiments and computer and graphic models. Am J Physiol Regul Integr Comp Physiol 1990; 259: R865-R877.

10 Abram SR, Hodnett BL, Summers RL, Coleman TG, Hester RL. Quantitative circulatory physiology: an integrative mathematical model of human physiology for medical education. Adv Physiol Educ 2007; 31: 202-210.

11 Crews DE, Williams SR. Molecular aspects of BP regulation. Hum Biol 1999; 71: 475-503.

12 Hall JE, Granger JP, Hester RL, Montani JP. Mechanisms of sodium balance in hypertension: role of pressure natriuresis. J Hypertens Supp/ 1986; 4: S57-S65.

13 Hall JE, Guyton AC, Smith MJ Jr, Coleman TG. BP and renal function during chronic changes in sodium intake: role of angiotensin. Am J Physiol Renal Physiol 1980; 239: F271-F280.

14 Palmer BF. Impaired renal autoregulation: implications for the genesis of hypertension and hypertension-induced renal injury. Am J Med Sci 2001; 321: 388-400.

15 Tripathy V, Gupta R. Blood pressure variation among Tibetans at different altitudes. Ann Hum Biol 2007; 34: 470-483.

16 Hanna JM. Climate, altitude, and blood pressure. Hum Biol 1999; 71: 553-582.

17 Roberts DF. Climate and Human Variability. Cummings: Menlo Park, CA, USA, 1978

18 Bergmann C. 'Über die Verhältnisse der Wärmeökonomie der Thiere zu ihrer Grösse'. Göttinger Studien 1847; 3: 595-708.

19 Blackburn TM, Gaston KJ, Loder N. Geographic gradients in body size: a clarification of Bergmann's rule. Diversity Distributions 1999; 5: 165-174.

20 Young JH, Chang YP, Kim JD, Chretien JP, Klag MJ, Levine MA, Ruff CB, Wang NY, Chakravarti A. Differential susceptibility to hypertension is due to selection during the out-of-Africa expansion. PLoS Genet 2005; 1: e82.

21 Jorgensen ME, Pedersen MB, Siggaard C, Sorensen TB, Mulvad G, Hansen JC, Skjolborg H, Pedersen EB. Ethnic, geographic and dietary influences upon vasoactive hormones and BP among Greenland Inuit and Danes. Blood Press 2003; 12 : 298-306.

22 Ejike CE, Ugwu CE, Ezeanyika LU, Olayemi AT. BP patterns in relation to geographic area of residence: a cross-sectional study of adolescents in Koji state, Nigeria. BMC Public Health 2008; 8: 411.

23 Fejerman L, Wu X, Adeyemo A, Luke A, Zhu X, Hicks C, Cooper RS. The effect of genetic variation in angiotensinogen on serum levels and BP: a comparison of Nigerians and US blacks. J Hum Hypertens 2006; 20: 882-887.

24 Whitfield KE, Yao X, Boomer KB, Vogler GP, Hayward MD, Vandenbergh DJ. Analysis of candidate genes and hypertension in African American adults. Ethn Dis 2009; 19 : $18-22$.

25 Nishimura H, Ogawa M. The renin-angiotensin system in fishes. Am Zool 1973; 13: 823-838.

26 Nishimura $\mathrm{H}$. Endocrine control of renal handling of solutes and water in vertebrates. Renal Physiol 1985; 8: 279-300.

27 Takei Y, Ogoshi M, Inoue K. A 'reverse' phylogenetic approach for identification of novel osmoregulatory and cardiovascular hormones in vertebrates. Front Neuroendocrinol 2007; 28: 143-160

28 Dombkowski RA, Russell MJ, Schulmann AA, Doellman MM, Olson KR. Vertebrate phylogeny and of hydrogen sulfite vasoactivity. Am J Physiol Regul Integr Comp Physiol 2005; 288: R243-R252.

29 Chobianan AV, Bakris GL, Black HR, Cushman WC, Green LA, Izzo JL Jr, Jones DW, Materson BJ, Oparil S, Wright JT Jr, Roccella EJ. Joint National Committee on Prevention, Detection, Evaluation, and Treatment of High Blood Pressure. National Heart, Lung, and Blood Institute; National High Blood Pressure Education Program Coordinating Committee. Seventh report of the Joint National Committee on Prevention, Detection, Evaluation, and Treatment of High BP. Hypertension 2003; 42: 1206-1252.

302007 World Health Organisation. Prevention of Cardiovascular Disease; Guidelines for Assessment and Management of Cardiovascular Risk. World Health Organization: Geneva, Switzerland, 2007.

31 Melamed S, Kristal-Boneh E, Froom P. Industrial noise exposure and risk factors for cardiovascular disease: findings from the CORDIS Study. Noise Health 1999; 4: $49-56$.

32 Stansfeld SA, Matheson MP. Noise pollution: non-auditory effects on health. Br Med Bull 2003; 68: 243-257.

33 Guyton AC. BP control: special role of the kidneys and body fluids. Science 1991; 252: $1813-1816$.

34 Guyton AC, Coleman TG, Cowley AW Jr, Scheel KW, Manning RD Jr, Norman RA Jr. Arterial pressure regulation: overriding dominance of the kidneys in long-term regulation and in hypertension. Am J Med 1972; 52: 584-594.

35 Moskowitz DW. Hypertension, thermotolerance, and the 'African gene': an hypothesis. Clin Exp Hypertens 1996; 18: 1525-6006.

36 Puddu M, Fanos V, Podda F, Zaffanello M. The kidney from prenatal to adult life.: perinatal programming and reduction of number of nephrons during development. $A m$ J Nephrol 2009; 30: 162-170.

37 Ambard L, Beaujard E. Causes de l'hypertension arterielle. Arch Int Med 1904; 1: 520.

38 Meneely GR, Tucker RG, Darby WJ, Auerbach SH. Chronic sodium chloride toxicity in the albino rat. II. Occurrence of hypertension and a syndrome of edema and renal failure. J Exp Med 1953; 98: 71-79.

39 Dahl LK. Salt and hypertension. Am J Clin Nutr 1972; 25: 231-244.

40 Prior IA, Evans JG, Harvey HP, Davidson F, Lindsey M. Sodium intake and BP in two Polynesian populations. N Engl J Med 1968; 279: 515-520. 
41 Elliot P, Marmot M. International studies of salt and BP. Ann Clin Res 1984; 16: 67-71.

42 INTERSALT Co-operative research Group. INTERSALT: an international study of electrolyte excretion and BP. Results for 24-hour urinary sodium and potassium. BMJ 1988; 297: 319-328.

43 Havas S, Roccella EJ, Lenfant C. Reducing the public health burden from elevated BP levels in the United States by lowering the intake of dietary sodium. Am J Pub Health 2004; 94: 19-22.

44 Sacks FM, Svetkey LP, Vollmer VM, Appel LJ, Bray GA, Harsha D, Obarzanek E, Conlin PR, Miller ER 3rd, Simons-Morton DG, Karanja N, Lin PH, DASH-Sodium Collaborative Research Group. Effects on BP of reduced dietary sodium and the dietary approaches to stop hypertension (DASH) diet. N Engl J Med 2001; 344: 3-10.

45 US Department of Agriculture. Continuing Study of Food Intakes of Individuals, 1994-1996. http://www.ars.usda.gov/services/docs.htm?docid=19476

46 O'Keefe JH Jr, Cordain L. Cardiovascular disease resulting from a diet and lifestyle at odds with our Paleolithic genome: How to become a 21st century hunter-gatherer. Mayo Clin Proc 2004; 79: 101-108.

47 Institute of Medicine, National Academies. Dietary Reference Intakes: Water Potassium, Sodium, Chloride, and Sulfate. National Academies Press: Washington, DC, USA, 2004; P6-1.

48 Hamilton BP, Blaustein MP. Molecular mechanisms linking sodium to hypertension: report of a symposium. J Investig Med 2006; 54: 86-94.

49 Wright JT Jr, Dunn JK, Cutler JA, Davis BR, Cushman WC, Ford CE, Haywood LJ, Leenen FH, Margolis KL, Papademetriou V, Probstfield JL, Whelton PK, Habib GB ALLHAT Collaborative Research Group. Outcomes in hypertensive black and nonblack patients treated with chlorthalidone, amlodipine, and lisinopril. JAMA 2005; 293 1595-1608.

50 Voors AW, Berenson GS, Dalferes ER, Webber LS, Shuler SE. Racial differences in BP control. Science 1979; 204: 1091-1094.

51 Woods JW, Pittman AW, Pulliam CC, Werk EE Jr, Waider W, Allen CA. Renin profiling in hypertension and its use in treatment with propranolol and chlorthalidone. $N$ Eng/ Med 1976; 294: 1137-1143.

52 Freis ED. Salt, volume and the prevention of hypertension. Circulation 1976; 53: 589.

53 Meneely GR, Battarbee HD. High sodium-low potassium environment and hypertension. Am J Cardiol 1976; 38: 768-785.

54 Walker WG, Whelton PK, Saito H, Russell RP, Hermann J. Relation between BP, and renin, renin substrate, angiotensin II, aldosterone and urinary sodium and potassium in ambulatory subjects. Hypertension 1979; 1: 287-291.

55 lacono JM, Marshall MW, Dougherty RM, Wheeler MA. Reduction in BP associated with high polyunsaturated fat diets that reduce blood cholesterol in man. Prev Med 1975; 4: 426-443.

56 Saunders JB, Beevers DG, Paton A. Alcohol-induced hypertension. Lancet 1981; 2: 653-656.

57 Wallace RB, Lynch CF, Pomrehn PR, Criqui MH, Heiss G. Alcohol and hypertension: epidemiologic and experimental considerations. The Lipid Research Clinics Program. Circulation 1981; 64: 41-47.

58 Neel JV. Diabetes mellitus: a thrifty genotype rendered detrimental by progress? Am J Hum Genet 1962; 14: 353-362.

59 Lev-Ran A, Porta M. Salt and hypertension: a phylogenetic perspective. Diabetes Metab Res Rev 2005; 21: 118-131.

60 Solomons NW, Gross R. Urban nutrition in developing countries. Nutr Rev 1995; 369: 39-48.

61 WHO Publication 2002. Globalization, Diets and Non-communicable Diseases. World Health Organisation: Switzerland.

62 Dinkel E, Ertel M, Dittrich M, Peters H, Berres M, Schulte-Wissermann H. Kidney size in childhood: sonographic growth charts for kidney length and volume. Pediatr Radiol 1985; 15: 38-43.

63 Perkkio J. The relationship between growth and allometry. J Theor Biol 1985; 113 81-87.

64 Weder AB, Schork NJ. Adaptation, allometry, and hypertension. Hypertension 1994 24: 145-156.

65 Brenner BM, Garcia DL, Anderson S. Glomeruli and BP: less of one, more of the other? Am J Hypertens 1988; 1: 335-347.

66 Hoy WE, Douglas-Denton RN, Hughson MD, Cass A, Johnson K, Bertram JF. A stereological study of glomerular number and volume: preliminary findings in a multiracial study of kidneys at autopsy. Kidney Int Supp/ 2003; 83: S31-S37.

67 Hoy WE, Bertram JF, Denton RD, Zimanyi M, Samuel T, Hughson MD. Nephron number, glomerular volume, renal disease and hypertension. Curr Opin Nephrol Hypertens 2008; 17: 258-265.

68 Hoy WE, Hughson MD, Singh GR, Douglas-Denton R, Bertram JF. Reduced nephron number and glomerulomegaly in Australian Aborigines: a group at high risk for renal disease and hypertension. Kidney Int 2006; 70: 104-110.

69 Keller G, Zimmer G, Mall G, Ritz E, Amann K. Nephron number in patients with primary hypertension. N Engl J Med 2003; 348: 101-108.

70 Kreutz R, Kovacevic L, Schulz A, Rothermund L, Ketteler M, Paul M. Effect of high $\mathrm{NaCl}$ diet on spontaneous hypertension in a genetic rat model with reduced nephron number. J Hypertens 2000; 18: 777-782.

71 Ashton N. Insulin-like growth factor, nephrogenesis and hypertension. J Hypertens 2006; 24: 1707-1709.

72 Wintour EM, Moritz KM, Johnson K, Ricardo S, Samuel CS, Dodic M. Reduced nephron number in adult sheep, hypt as a result of prenatal glucocorticoid treatment. $J$ Physiol 2003; 549: 929-935.
73 Douglas-Denton RN, McNamara BJ, Hoy WE, Hughson MD, Bertram JF. Does nephron number matter in the development of kidney disease? Ethn Dis 2006; Vol 16 Spring S2-40-S2-45.

74 Holliday MA, Potter D, Jarrah A, Bearg S. The relation of metabolic rate to body weight and organ size. Pediatr Res 1967; 1: 185-195.

75 Nyengaard JR, Bendtsen TF. Glomerular number and size in relation to age, kidney weight and body surface in normal man. Anat Rec 1992; 232: 194-201.

76 Bagby SP. Maternal nutrition, low nephron number, and hypertension in later life pathways of nutritional programming. J Nutr 2007; 137: 1066-1072.

77 Hales CN, Barker DJ. Type 2 (non-insulin-dependent) diabetes mellitus: the thrifty phenotype hypothesis. Diabetologia 1992; 35: 595-601.

78 Hoet JJ, Hanson MA. Intrauterine nutrition: its importance during critical periods for cardiovascular and endocrine development. J Physiol 1999; 514: 617-627.

79 Kuwahara E, Asakura K, Nishiwaki Y, Komatsu H, Nakazawa A, Ushiku H, Maejima F, Nishigaki Y, Hasegawa T, Okamura T, Takebayashi T. Steeper increases in body mass index during childhood correlate with blood pressure elevation in adolescence: a longterm follow-up study in a Japanese community. Hypertens Res 2014; 37: 179-184.

80 Zhang Y, Li H, Liu SJ, Fu GJ, Zhao Y, Xie YJ, Zhang Y, Wang YX. The associations of high birth weight with blood pressure and hypertension in later life: a systematic review and meta-analysis. Hypertens Res 2013; 36: 725-735.

81 Harrison M, Langley-Evans SC. Intergenerational programming of impaired nephrogenesis and hypertension in rats following maternal protein restriction during pregnancy. Br J Nutr 2009; 101: 1020-1030.

82 Ijzerman RG, Boomsma DI, Stehouwer CD. Intrauterine environmental and genetic influences on the association between birthweight and cardiovascular risk factors: studies in twins as a means of testing the fetal origins hypothesis. Paediatr Perinat Epidemiol 2005; 19: 10-14.

83 Zanardo V, Visentin S, Trevisanuto D, Bertin M, Cavallin F, Cosmi E. Fetal aortic wall thickness: a marker of hypertension in IUGR children? Hypertens Res 2013; 36 : 440-443.

84 Boubred F, Buffat C, Feuerstein JM, Daniel L, Tsimaratos M, Oliver C, LelièvrePégorier M, Simeoni U. Effects of early postnatal hypernutrition on nephron number and long-term renal function and structure in rats. Am J Physiol Renal Physiol 2007; 293: F1944-F1949.

85 Ingelfinger JR. Pathogenesis of perinatal programming. Curr Opin Nephrol Hypertens 2004; 13: 459-464.

86 Geller DS. A mineralocorticoid receptor mutation causing human hypertension. Curr Opin Nephrol Hypertens 2001; 10: 661-665.

87 Wilson FH, Disse-Nicodeme S, Choate KA, Ishikawa K, Nelson-Williams C, Desitter I, Gunel M, Milford DV, Lipkin GW, Achard JM, Feely MP, Dussol B, Berland Y, Unwin RJ, Mayan H, Simon DB, Farfel Z, Jeunemaitre X, Lifton RP. Human hypertension caused by mutations in WNK kinases. Science 2001; 293: 1107-1112.

88 Zhang D, Yu ZY, Cruz P, Kong Q, Li S, Kone BC. Epigenetics and the control of epithelial sodium channel expression in collecting duct. Kidney Int 2009; 75 260-267.

89 Davis N. The cardiovascular and renal relations and manifestations of gout. JAMA 1897; 29: 261-262.

90 Watanabe S, Kang DH, Feng L, Nakagawa T, Kanellis J, Lan H, Mazzali M, Johnson RJ. Uric acid, hominoid evolution, and the pathogenesis of salt-sensitivity. Hypertension 2002; 40: 355-360

91 Vitart V, Rudan I, Hayward C, Gray NK, Floyd J, Palmer CN, Knott SA, Kolcic I, Polasek O, Graessler J, Wilson JF, Marinaki A, Riches PL, Shu X, Janicijevic B, Smolej-Narancic N, Gorgoni B, Morgan J, Campbell S, Biloglav Z, Barac-Lauc L, Pericic M, Klaric IM, Zgaga L, Skaric-Juric T, Wild SH, Richardson WA, Hohenstein P, Kimber $\mathrm{CH}$, Tenesa A, Donnelly LA, Fairbanks LD, Aringer M, McKeigue PM, Ralston $\mathrm{SH}$, Morris AD, Rudan P, Hastie ND, Campbell H, Wright AF. SLC2A9 is a newly identified urate transporter influencing serum urate concentration, urate excretion and gout. Nat Genet 2008; 40: 437-442.

92 Johnson RJ, Segal MS, Sautin Y, Nakagawa T, Feig DI, Kang DH, Gersch MS, Benner S, Sánchez-Lozada LG. Potential role of sugar (fructose) in the epidemic of hypertension, obesity and the metabolic syndrome, diabetes, kidney disease, and cardiovascular disease. Am J Clin Nutr 2007; 86: 899-906.

93 Hallfrisch J. Metabolic effects of dietary fructose. FASEB J 1990; 4: 2652-2660.

94 Brown CM, Dulloo AG, Yepuri G, Montani JP. Fructose ingestion acutely elevates BP in healthy young humans. Am J Physiol Regul Integr Comp Physiol 2008; 294: R730-R737.

95 Nakagawa T, Hu H, Zharikov S, Tuttle KR, Short RA, Glushakova O, Ouyang X, Feig DI, Block ER, Herrera-Acosta J, Patel JM, Johnson RJ. A causal role for uric acid in fructose-induced metabolic syndrome. Am J Physiol Renal Physiol 2006; 290: F625-F631.

96 Perlstein TS, Gumieniak O, Williams GH, Sparrow D, Vokonas PS, Gaziano M, Weiss ST, Litonjua AA. Uric acid and the development of hypertension: the normative aging study. Hypertension 2006; 48: 1031-1036.

97 Shankar A, Klein R, Klein BE, Nieto FJ. The association between serum uric acid and long-term incidence of hypertension: population-based cohort study. J Hum Hypertens 2006; 20: 937-945

98 Alper AB Jr, Chen W, Yau L, Srinivasan SR, Berenson GS, Hamm LL. Childhood uric acid predicts adult BP: the Bogalusa Heart Study. Hypertension 2005; 45: 34-38.

99 Feig DI, Kang DH, Johnson RJ. Uric acid and cardiovascular risk. N Engl J Med 2008; 359: 1811-1821.

100 Syamala S, Li J, Shankar A. Association between serum uric acid and prehypertension among US adults. J Hypertens 2007; 25: 1583-1589. 
101 Feig DI, Nakagawa T, Karumanchi SA, Oliver WJ, Kang DH, Finch J, Johnson RJ. Hypothesis: uric acid, nephron number, and the pathogenesis of essential hypertension. Kidney Int 2004; 66: 281-287.

102 Oluwole OB, McMillen M, Sumpio B. Endothelial cell control of vasomotor tone. Ann Vasc Surg 1995; 9: 293-301.

103 deNucci G, Thomas R, D'Orleans-Juste P. Pressor effects of circulating endothelin are limited by its removal in the pulmonary circulation and by the release of prostacyclin and endothelium-derived relaxing factor. Proc Natl Acad Sci USA 1988; 85: 9797-9800.

104 Schrier RW, Abraham WT. Hormones and hemodynamics in heart failure. $N$ Eng/ J Med 1999; 341: 577-585.

105 Loscalzo J. An experiment of nature: genetic L-arginine deficiency and NO insufficiency. J Clin Invest 2001; 108: 663-664.

106 Rask-Madsen C, King GL. Mechanisms of disease: endothelial dysfunction in insulin resistance and diabetes. Nat Clin Pract Endocrinol Metab 2007; 3: 46-56.

107 Fish JE, Marsden PA. Endothelial nitric oxide synthase: insight into cell-specific gene regulation in the vascular endothelium. Cell Mol Life Sci 2006; 63: $144-162$.

108 Fish JE, Matouk CC, Rachlis A, Lin S, Tai SC, D'Abreo C, Marsden EA. The expression of endothelial nitric-oxide synthase is controlled by a cell-specific clone. J Biol Chem 2005; 280: 24824-24838.

109 Solhaug MJ, Bolger PM, Jose PA. The developing kidney and environmental toxins. Pediatrics 2004; 113: 1084-1091.
110 Lee DH, Lee IK, Song K, Steffe M, Toscano W, Baker BA, Jacobs DR Jr. A strong doseresponse relation between serum comncentrations of persistent organic pollutants and diabetes: results from the National Health and Examination Survey 1999-2002. Diabetes Care 2006; 29: 1638-1644.

111 Wang YR, Zhang M, Wang Q, Yang DY, Li CL, Liu J, Li JG, Li H, Yang XY. Exposure of mother-child and postpartum woman-infants pairs to DDT and its metabolites in Tianjing China. Sci Total Environ 2008; 396: 34-341.

112 Patandin S, Koopman-Esselboom C, de Ridder MA, Weisglas-Kuperus N, Sauer PJ. Effects of environmental exposure to polychlorinated biphenyls and dioxin on birth size and growth in Dutch children. Pediatr Res 1998; 44: 538-545.

113 Kreiss K, Zack MM, Kimbrough RD, Needham LL, Smrek MD, Jones BT. Association of BP and polychlorinated biphenyl levels. JAMA 1981; 245: 2505-2509.

114 Everett CJ, Mainous AG 3rd, Frithsen IL, Player MS, Matheson EM. Association of polychlorinated biphenyls with hypertension in the 1990-2002 National Health and Nutrition Examination Survey. Environ Res 2008; 108: 94-97.

115 Rusiecki JA, Baccarelli A, Bollati V, Tarantini L, Moore LE, Bonefeld- Jorgensen EC. Global DNA hypomethylation is associated with high serum-persistent organic pollutants in Greenlandic Inuit. Environ Health Perspect 2008; 116: 1547-1552.

116 Anway MD, Skinner MK. Epigenetic programming of the germline: effects of endocrine disruptors on the development of transgenerational disease. Reprod Biomed Online 2008; 16: 23-25. 